\title{
QUANTIFICATION OF NEURAL ELEMENTS IN POSTERIOR CRUCIATE LIGAMENT: COMPARISON BETWEEN HEALTHY KNEES AND WITH PRIMARY OSTEOARTHROSIS
}

\section{QUANTIFICAÇÃO DOS ELEMENTOS NEURAIS NO LIGAMENTO CRUZADO POSTERIOR: COMPARAÇÃO ENTRE JOELHOS HÍGIDOS E COM OSTEOARTROSE PRIMÁRIA}

\author{
1. Federal University of Cariri, Faculty of Medicine, Barbalha, CE, Brazil. \\ 2. Federal University of Pernambuco, Department of Pathology, Recife, PE, Brazil. \\ 3. Federal Rural University of the Semi-Arid Region, Mossoró, RN, Brazil. \\ 4. Federal University of Ceará, Department of Surgery, Fortaleza, CE, Brazil.
}

Marcelo Parente Oliveira ${ }^{1}$ (1), Roberto José Vieira de Mello ${ }^{2}$ (i), Luciano Tavares Montenegro ${ }^{2}$ (1), Silvania TAVAREs PaZ ${ }^{2}$ (1), Diego ARIEL de LIMA ${ }^{3}$ (1), José Alberto Dias LeITE ${ }^{4}$ (1)

\section{ABSTRACT}

Objective: To quantify the neural elements in the posterior cruciate ligament $(\mathrm{PCL})$ in healthy knees and with primary osteoarthrosis (OA). Methods: In two groups with OA, one of cadavers and another of individuals, the area of neural elements identified in histological sections of PCL with anti-S100 immunohistochemistry was quantified. Results: The overall mean area of the neural elements was $0.96 \% \pm 0.67 \%$, with the value in the cadaver group of $1.02 \% \pm 0.67 \%$ and in the OA group of $0.80 \% \pm 0.64 \%$, with a significant statistically difference $(p=0.001)$. No correlation was observed between neural element quantification and the age of the individuals $(p>0.05)$. There was no difference in the quantification of neural elements between the sexes in the cadaver group $(p=0.766)$, but in the OA group there was a statistically significant reduction in males $(p=0.003)$. Also, in the osteoarthrosis group there was no difference in the quantification of neural elements in the knees with varus or valgus alignment $(p=0.847)$. Conclusion: There was a decrease in neural element quantification in PCL of individuals affected by OA in relation to non-arthritic individuals, with this quantification not related to age or with the axis of the lower limb. However, this quantification is not related to age or the axis of the lower limb. Level of Evidence III, Case control study.

Keywords: Posterior Cruciate Ligament. Mechanoreceptors. Nerve Tissue. Immunohistochemistry. Osteoarthritis.
RESUMO

Objetivo: Quantificar os elementos neurais no ligamento cruzado posterior (LCP) em joelhos hígidos e com osteoartrose primária (OA). Métodos: Em um grupo de cadáveres e outro de indivíduos com ao, foi realizada a quantificação da área dos elementos neurais identificados em cortes histológicos do LCP com imunohistoquímica anti-S100. Resultados: A média geral da área dos elementos neurais foi $0,96 \% \pm 0,67 \%$, com o valor no grupo cadáver de $1,02 \% \pm 0,67 \%$ e no grupo OA de $0,80 \% \pm 0,64 \%$, havendo uma diferença estatisticamente significante $(p=0,001)$. Não se observou correlação entre a quantificação dos elementos neurais e a idade dos indivíduos ( $p>0,05)$. Não se observou diferença na quantificação dos elementos neurais entre os sexos no grupo cadáver ( $p=0,766)$, mas no grupo OA se observou redução estatisticamente significante no sexo masculino $(p=0,003)$. No grupo OA não houve diferença na quantificação dos elementos neurais nos joelhos com alinhamento varo ou valgo ( $p=0,847)$. Conclusão: Foi demonstrada uma redução na quantificação dos elementos neurais no LCP de indivíduos acometidos por OA em relação aos indivíduos não artrósicos, com essa quantificação não tendo relação com idade nem com o eixo do membro inferior. Nível de evidência III, Estudo de caso controle.

Descritores: Ligamento Cruzado Posterior. Mecanorreceptores. Tecido Neural. Imuno-Histoquímica. Osteoartrose.

Citation: Oliveira MP, Mello RJV, Montenegro LT, Paz ST, Lima DA, Leite JAD. Quantification of neural elements in posterior cruciate ligament: comparison between healthy knees and with primary osteoarthrosis. Acta Ortop Bras. [online]. 2021;29(5):253-257. Available from URL: http://www.scielo.br/aob.

\section{INTRODUCTION}

Mechanoreceptors are responsible for detecting the deformation of periarticular tissues and for the sensory coding of signals that inform about intrinsic and extrinsic joint forces. These signals offer the cognitive perception of the strength, positioning, movement, speed and direction to which the joint is submitted, contributing indispensablely to joint homeotasis. ${ }^{1-3}$

All authors declare no potential conflict of interest related to this article.

The study was conducted at the Federal University of Ceará.

Correspondence: Marcelo Parente Oliveira. Rua Divino Salvador, 284, Rosário, Barbalha, CE, Brazil, 63180000. marceloparente03@hotmail.com 
Osteoarthrosis (OA) is marked by capsuloligamentous laxity, loss of articular cartilage, bone deformity and limb misalignment, factors that strongly influence the loss of proprioceptive sensitivity. It is also observed the decline in proprioceptive capacity with the aging process, which also has an important relevance when observing the degenerative joint disease, characteristically incident in older age groups. ${ }^{1,4}$ The joint replacement through arthroplasty has led to proprioceptive sensitivity at an intermediate level between the disease status and the normal, with the objective of restoring limb alignment, soft tissue balance and joint stability. The knees with more accurate proprioceptive capacity may be related to the load applied more physiologically, which is important in preventing the loosening and the wearing of arthroplasty implants. ${ }^{4-6}$

Several studies examined the difference in proprioceptive capacity after the total knee arthroplasty (TKA) and compared the results of several joint reconstruction techniques, particularly the preservation or not of the posterior cruciate ligament (PCL), among other reasons, for believing that this structure has an important proprioceptive function, ${ }^{4-6}$ being demonstrated and studied the mechanoreceptors in the posterior cruciate ligament of the knee. ${ }^{2,3,7-12}$ However, benefits with the preservation of PCL have not been consistently observed. This may be related to a reduction in the population of mechanoreceptors with the advancing age and even faster in $\mathrm{OA} .2 .8,11,13,14$

The aim of this study was to analyze the neural elements in PCL and to verify whether there is; a reduction in the quantification of neural elements in $\mathrm{OA}$; a correlation with the age of the individuals investigated exists; a difference between males and females; and a difference between arthritic knees with varus or valgus alignment.

\section{MATERIALS AND METHODS}

This study, developed from July 2017 to December 2019, was conducted in accordance with the Helsinki Declaration of 1995, and was analyzed and approved by the Research Ethics Committee of the Medical School of Universiade Federal do Cariri (UFCA) (CAAE: 31115014.9.0000.5035). Two groups of individuals were studied, one consisting of fresh cadavers and another by patients with primary knee OA. All individuals studied or their legal guardians signed a Free and Informed Consent Form.

In the cadaver group, both sexes were included, with no age restrictions, and 24 PCLs of 24 cadavers with no morbid past in the joint were studied. The knee side was chosen by drawing lots. Macroscopic examination of the joint, as well as the medical, cadaveric and interrogation reports to family members or guardians were evaluated to make sure that there were no previous knee injuries. Cadavers with history or evidence of previous morbidity, inflammatory diseases and surgical past in the joint were excluded. The cadaver was positioned in ventral decubitus and through a posterior access to the knee, and the PCL was collected from the femoral insertion until the tibial insertion.

In the OA group, both sexes were included, with no age restrictions, and 14 PCLs of patients with primary OA, submitted to TKA with posterior stabilization, were studied. Patients with secondary $\mathrm{OA}$ and previous knee surgery were excluded. For collection during the TKA surgical procedure, after medial parapatellar arthrotomy and lateral dislocation of the patella, with the knee at maximum flexion, the osteophytes and anterior cruciate ligament $(A C L)$ were resected, when present in the femoral intercondylar, the anteriorization of the tibia under the femur and proximal tibial cut, allowing the collection of PCL from its femoral insertion to tibial insertion.
The preliminary study with hematoxylin-eosin (HE) staining showed in all specimens evaluated ligament tissue with fibers and typical cells, and periligamentous and vasculonervous tissues of normal aspects. It did not show any pathological condition that could compromise the study of neural elements in the conditions proposed in the research.

For each ligament, a slide with anti-S100 immunohistochemistry (murine monoclonal antibody Clone 4C4.9 - ZETA Corporation) was prepared using the method as described by Kahn et al. ${ }^{15}$ and by Mihalko et $\mathrm{al} .{ }^{16}$ following the processing and reaction according to the manufacturer's protocol.

The anti-S100 stained slide were analyzed by a Master of Prosthetics and Orthotics (M.P.O) and two doctors, professors of pathology, (R.J.V.M and L.T.M). An optical microscopy study was carried out with an increase of 100× (DI-115T microscope, DIGILAB Laboratory). Microscopic, and the visualization was performed throughout the entire tissue present in the slide. When anti-S100 stained neural tissue was identified in the field of vision of microscopy, the image was captured with a digital camera (model A59.4910, DIGILAB Laboratório) coupled to the microscope and the Micro Capture software (Ver6.9.12). The images were standardized in files with TIFF format. In each slide, the maximum number of images viewed was collected. All images were captured respecting the same standardization of magnification in microscopy, resolution and image size (Figure 1). ${ }^{17}$

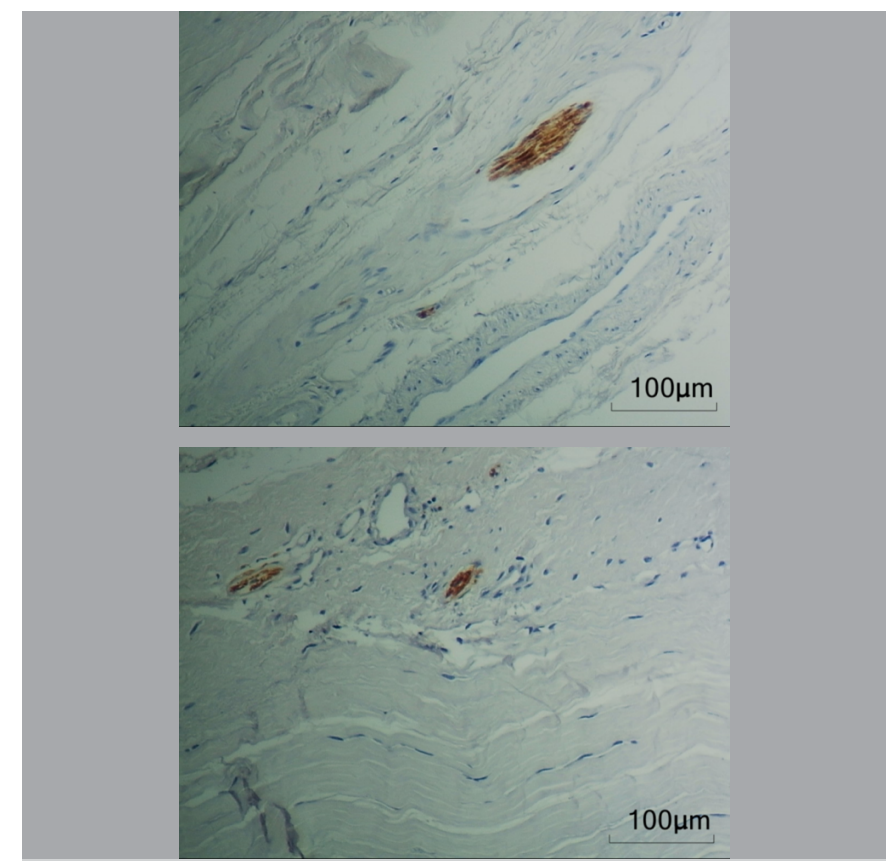

Figure 1. Histological sections of the PCL in case of the cadaver group (right) and OA (left). Staining with anti-S100 immunohistochemistry in which the presence of neural elements is evidenced in an increase of 100 times.

The images, standardized in size $1024 \times 768$ pixels with $96 \mathrm{dpi}$ (dots per inch) RGB color, 1 layer, with a total of 786.432 pixels, were analyzed with the software GIMP 2.10.14 (GNOME Foundation). With this software, the "free hand" selection of the area corresponding to the neural tissue observed in the image was performed (Figure 2) and the pixels referring to the selected area (Figure 3$)^{17}$ were counted. The amount of pixels referring to neural tissues was recorded for each image as a percentage of the total pixels of the image. 


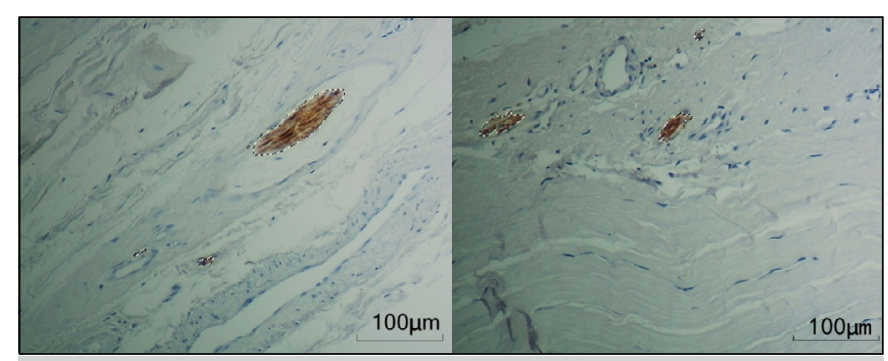

Figure 2. Selection of areas corresponding to neural elements in Figure 1
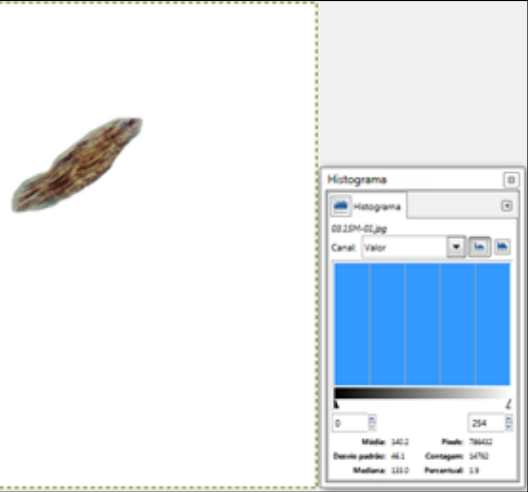

Figure 3. Quantification of neural elements through a histogram in channel value with subtraction of the value 255 of the white color of the background of the image, with pixel count corresponding to the neural elements as a percentage of the total pixels in Figure 2.
The data were tabulated and analyzed with the software Statistical Package for the Social Sciences (IBM-SPSS, version 24). A p-value of 0.05 was set for statistical significance.

\section{RESULTS}

Table 1 describes the distribution of individuals by gender and age. There was no statistically significant difference between the groups in relation to age $(p=0.256)$ and gender $(p=0.088)$ of the individuals.

Table 1. Sample distribution by age and gender

\begin{tabular}{c|c|c|c}
\hline \multirow{2}{*}{ Age } & \multicolumn{2}{|c|}{ Group } & \multirow{2}{*}{ p-value } \\
\cline { 2 - 3 } & Cadaver & Osteoarthritis & \\
\hline Average & & & 0.256 \\
\hline Standard Deviation & 59.8 & 71.1 & \\
\hline $95 \% \mathrm{Cl}$ & 24.4 & 8,4 & \\
\hline Minimum & $139.5-70.1)$ & $(62.2-75.9)$ & \\
\hline Median & 64.5 & 57 & \\
\hline Maximum & 92 & 70.5 & \\
\hline Sex & & 87 & 0.088 \\
\hline Male & 13 & & \\
\hline Female & 11 & 3 & \\
\hline
\end{tabular}

Note: $\left(^{*}\right) p<0.05$ Kruskal-Wallis test

A total of 374 microscopy fields were recorded, 276 in the cadaver group and 98 in the OA group. The overall mean area of neural elements was $0.96 \% \pm 0.67 \%$ for both groups together, and in the cadaver group it was $1.02 \% \pm 0.67 \%$ and in the OA group it was $0.80 \% \pm 0.64 \%$, with \pm statistically significant reduction in the $\mathrm{OA}$ group ( $p=0.001$ ) (Table 2 and Figure 4$)$.

Table 2. Quantification of the area of neural elements (\%) per profile under analysis.

\begin{tabular}{|c|c|c|c|c|c|c|c|c|}
\hline & \multirow{2}{*}{$\mathbf{N}$} & \multirow{2}{*}{ Average } & \multirow{2}{*}{$\begin{array}{l}\text { Deviation } \\
\text { Standard }\end{array}$} & \multicolumn{2}{|c|}{$95 \% \mathrm{Cl}$} & \multirow{2}{*}{ Minimum } & \multirow{2}{*}{ Maximum } & \multirow{2}{*}{$p$-value } \\
\hline & & & & LL & UL & & & \\
\hline General & 374 & 0.96 & 0.67 & 0.89 & 1.03 & 0.07 & 2.75 & \\
\hline Groups & & & & & & & & 0.001 \\
\hline Cadaver & 276 & 1.02 & 0.67 & 0.94 & 1.10 & 0.09 & 2.75 & \\
\hline Osteoarthritis & 98 & 0.80 & 0.64 & 0.67 & 0.93 & 0.07 & 2.46 & \\
\hline $\begin{array}{c}\text { Groups } \\
\text { (Over } 60 \text { years) }\end{array}$ & & & & & & & & 0.001 \\
\hline Cadaver & 188 & 1.04 & 0.66 & 0.94 & 1.13 & 0.13 & 2.75 & \\
\hline Osteoarthritis & 90 & 0.81 & 0.65 & 0.67 & 0.94 & 0.97 & 2.46 & \\
\hline Cadaver Group & & & & & & & & 0.766 \\
\hline Male & 153 & 1.04 & 0.71 & 0.93 & 1.16 & 0.09 & 2.75 & \\
\hline Female & 123 & 0.99 & 0.62 & 0.88 & 1.10 & 0.13 & 2.66 & \\
\hline Osteoarthrosis Group & & & & & & & & 0.003 \\
\hline Male & 23 & 0.45 & 0.32 & 0.31 & 0.59 & 0.07 & 1.13 & \\
\hline Female & 75 & 0.91 & 0.68 & 0.75 & 1.06 & 0.12 & 2.46 & \\
\hline Osteoarthrosis Group & & & & & & & & 0.847 \\
\hline Varus & 84 & 0.81 & 0.66 & 0.66 & 0.94 & 0.07 & 2.46 & \\
\hline Valgus & 14 & 0.77 & 0.55 & 0.45 & 1.08 & 0.21 & 1.82 & \\
\hline
\end{tabular}

*Kruskal-Wallis test 


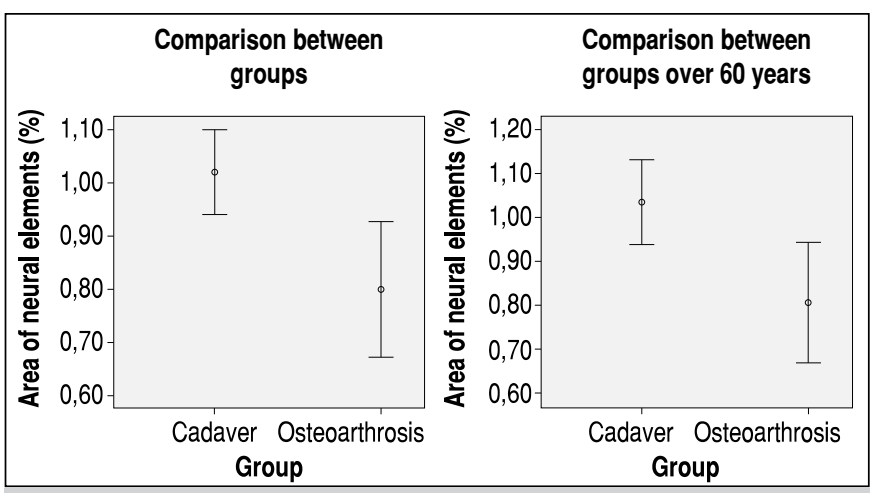

Figure 4. Means of neural element areas with $95 \% \mathrm{Cl}$ in relation to the group.

In order to minimize age bias in comparison, considering that the OA group is composed almost entirely of individuals over 60 years of age, groups including only individuals above this age group were compared. Nevertheless, the observation of a statistically significant reduction in the area of neural elements of the OA group was maintained ( $p=0.001$ ) (Table 2 and Figure 4$)$.

There was no correlation between the age of the individuals studied and the area of the neural elements either in the cadaver group $(p=0.521)$ or in the OA group $(p=0.079)$ (Figure 5$)$.

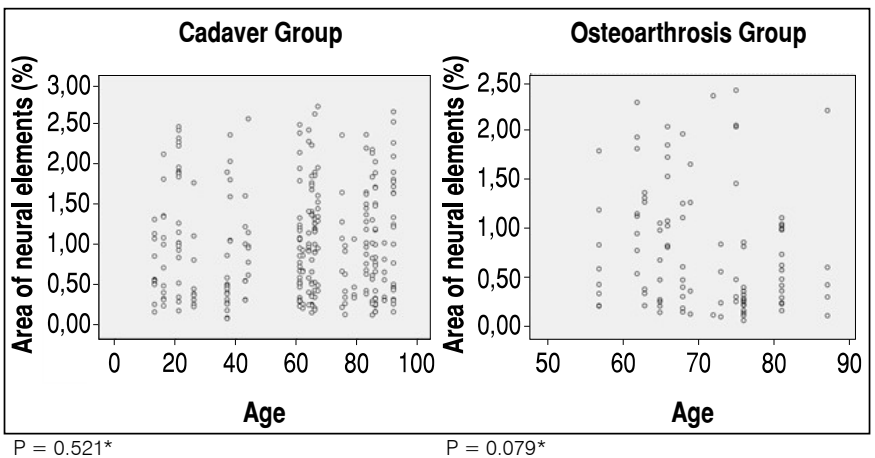

Figure 5. Scatter plots between age and quantification of the area of neural elements.

*: Pearson linear correlation

In the cadaver group there was no statistically significant difference in the mean area of neural elements between the sexes $(p=0.766)$. In the OA group, there was a statistically significant reduction in males in relation to females $(p=0.003)$ (Table 2 and Figure 6).

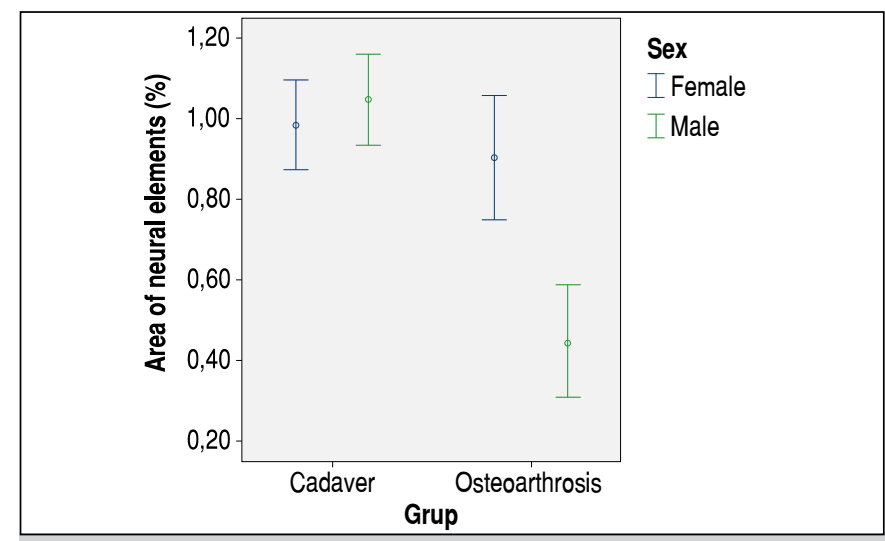

Figure 6. Means of neural element areas with $95 \% \mathrm{Cl}$ in relation to gender and group.
In the OA group there was no statistically significant difference in the area of neural elements between the knees with varus and valgus alignment $(p=0.847)$ (Table 2$)$.

\section{DISCUSSION}

In the present study, the overall mean of the area occupied by neural elements per field of microscopy was $0.96 \% \pm 0.67$. In healthy knees, this mean was $1.02 \% \pm 0.67 \%$, comparable to the values of $0.958 \% \pm 0.13 \%$ found in the healthy knees studied by Franchi, Zaccherotti and Aglietti1 ${ }^{11}$ and at the value of $1 \%$ found by Schutte et al. ${ }^{18}$ in the anterior cruciate ligament of healthy knees. On the knees with $\mathrm{OA}$, in the present study we found an average of $0.83 \% \pm 0.67 \%$, being higher than the average found by Franchi, Zaccherotti and Aglietti ${ }^{11}$ in their group of arthrosic knees, which was $0.44 \% \pm 0.132 \%$. Zhang and Mihalko found quite different values of percentage of area occupied by neural elements in histological images studying two groups of knees with $\mathrm{OA}$. In one group involving recovered TKA-CR PCLs, the average stained area in the cross-section studied by microscopy was $10.7 \% \pm 5.1 \%$ in anti-S100 immunohistochemistry. In the second group, consisting of PCLs collected from TKA-PS, the average stained area was $11.1 \% \pm 7 \%$ anti-S100. The authors did not observe a statistically significant difference in the area of the receptors between the groups. This large discrepancy in the areas in relation to the studies by Schutte et al. ${ }^{18}$ Franchi, Zaccherotti and Aglietti ${ }^{11}$ and the present study may be due to different methodology in microscopic and/or histomorphometric study.

In the comparison between groups, Del Valle et al.12 did not observe significant difference between the types of corpuscles, sizes and distribution between knees with OA and healthy. Franchi, Zaccherotti and Aglietti ${ }^{11}$ observed a statistically significant reduction in the area occupied by the neural network and mechanoreceptors in the $P C L$ of the knees with OA in relation to normal knees $(p=0.001)$, findings similar to those of Çabuk et al., ${ }^{2}$ that although they did not find a difference between knee groups with $O A$ and normal with regard to the number of Pacini corpuscles, they observed that the number of Ruffini corpuscles, Golgi, free nerve endings and total nerve endings was significantly lower in the OA group $(p<0.05)$. Marczack et al. ${ }^{3}$ observed in patients with primary OA a correlation between the severity of radiographic alterations and the presence of neural elements in PCL $(p<0.0001)$, so that samples with high degrees of degeneration had few receptors. They also observed a significant statistically decrease in the number of neural elements in patients with $\mathrm{OA}$ in relation to cadavers without joint disease $(p<0.0001)$. In the present study, a significant statistically reduction in the area of neural elements was observed in the OA group in relation to the cadaver group ( $p=0.001)$, even with the comparison between groups with paired ages above 60 years $(p=0.001)$, reinforcing the role of $O A$ in reducing the quantification of neural elements in $\mathrm{PCL}$, since both groups were equated to the same age group.

The influence of age on the characteristics of neural elements in PCL has been verified in some studies. Moreno et al., ${ }^{7}$ who studied 15 PCLs of cadavers without joint morbidity, did not observe a correlation between the age of the cadaver and the total number of mechanoreceptors. A finding similar to that of Martins, Camanho and Rodrigues,$^{10}$ who identified immunomarkers for neural structures in $67.5 \%$ of the $34 \mathrm{PCLs}$ of patients with primary OA, but did not observe a correlation between the age of the patients and the presence of neural elements. Colleoni et al., ${ }^{8}$ studying a male population of 19 cadavers without joint morbidity, did not observe a significant relationship between the total number of mechanoreceptors and age in the femoral or tibial portions of the PCL. However, in the tibial insertion, they observed a statistically 
significant inverse correlation between age and the number of type I and type III mechanoreceptors, indicating that the older the age, the lower the number of these types of receptors in the tibial portion. In the present study, it was observed that there was no correlation between the mean area of neural elements and the age of the individuals evaluated both in the cadaver group and in the OA group. Thus, it is evident in the sample studied that the aging process was not related to a reduction in the quantification of neural elements in PCL.

Moreno et al. ${ }^{7}$ and Colleoni et al. ${ }^{8}$ point out that they did not find data in the literature demonstrating or suggesting the need for a comparative study in relation to gender, thus, they included only male individuals in an attempt to standardize their samples. In their work, Martins, Camanho and Rodrigues ${ }^{10}$ observed that there was no association between sex and the presence of neural elements. In the present study, it was observed that in the knees of the cadaver group there was no difference in the quantification of the area of neural elements between the sexes $(p=0.766)$. However, in the OA group, there was a lower quantification of the area of neural elements in males than in females ( $p=0.003$ ). It is evident, that although the literature does not pay attention to the difference in the quantification of neural elements in knee PCL between the sexes, this variable is necessary in order to better understand the characteristics of neural structures in knee PCL. This need reinforces the discussion about the differences between the sexes not only in some aspects of proprioception, but also in studies evaluating the knee joint.19.20

Evaluating the neural elements and their behavior in relation to knee alignment in varus or valgus, Martins, Camanho and Rodrigues ${ }^{10}$ observed that neural structures were more frequent in varus knees $(77 \%)$ than in the valgus (50\%), statistically significant difference $(p=0.048)$. In opposition, in the present study, no statistically significant difference was observed in the quantification of neural elements between the varus and valgus knees $(p=0.847)$. No other study was identified that evaluated limb alignment and neural elements in PCL.
There is no data in the literature to suggest any observation about the laterality or dominance of the limb in the study of neural elements. This study also did not analyze these variables, although it does not rule out the relevance of studying the subject, particularly in view of the interest in the discussion about the laterality or dominance of the limb and its relationship with proprioception. ${ }^{19,20}$

Limitations for the study are the number of slides prepared for each ligament. Although it is believed that a greater number of histological sections could provide better representativeness of the neural elements in the analyzed ligaments, the standardization of histological and histomorphometric methodology partially circumvent this problem. Another technical limitation is the non-standardization of histological sections in relation to ligament regions, i.e., femoral, tibial and medium substance bone insertions. The systematized study with search for neural elements along the entire histological slide minimizes this limitation, since all the cutting tissue could be examined.

Knowing the characteristics of neural elements in PCL, particularly under different sexes, ages, morbidity conditions, laterality and dominance may support therapeutic decisions, such as the indication of resection or not of the posterior cruciate ligament when performing a TKA, assisting in the identification of specific groups that may be better conducted under one form or another of treatment. In another case, the knowledge of specific groups with greater vulnerability from the proprioceptive perspective may help in the planning, development and indication of preventive measures against acute or chronic joint injuries.

\section{CONCLUSION}

A reduction was demonstrated in the quantification of neural elements in PCL of individuals affected by OA, compared to non-arthritic individuals, and this quantification is not related to age or the mechanical axis of the lower limb.

AUTHORS' CONTRIBUTION: Each author contributed individually and significantly to the development of this article. MPO: conception and writing of the article, acquisition, analysis and interpretation of the data; RJVM: analysis and interpretation of histological studies; LTM: analysis and interpretation of histological studies; STP: execution of histology papers; DAL: critical review of the article; JADL: critical review and intellectual concept of the article.

\section{REFERENCES}

1. Wodowski AJ, Swigler CW, Liu H, Nord KM, Toy PC, Mihalko WM. Proprioception and knee arthroplasty: a literature review. Orthop Clin North Am. 2016;47(2):301-9.

2. Çabuk H, Çabuk FK, Tekin AÇ, Dedeo lu SS, Çakar M, Büyükkurt CD. Lower numbers of mechanoreceptors in the posterior cruciate ligament and anterior capsule of the osteoarthritic knees. Knee Surg Sports Traumatol Arthrosc. 2017;25(10):3146-54.

3. Marczak D, Kowalczewski J, Oko T, Synder M, Sibi ski M. An evaluation of the posterior cruciate ligament function in total knee arthroplasty with regard to its morphology and clinical properties. Folia Morphol (Warsz). 2017;76(1):94-9.

4. Barrett DS, Cobb AG, Bentley G. Joint proprioception in normal, osteoarthritic, and replaced knees. J Bone Joint Surg Br. 1991;73(1):53-6.

5. Pap G, Meyer M, Weiler HT, Machner A, Awiszus F. Proprioception after total knee arthroplasty: A comparison with clinical outcome. Acta Orthop Scand. 2000;71(2):153-9.

6. Swanik CB, Lephart SM, Rubash HE. Proprioception, kinesthesia, and balance after total knee arthroplasty with cruciate-retaining and posterior stabilized prostheses. J Bone Joint Surg Am. 2004;86(2):328-34.

7. Moreno CT, Carvalho RL, Colleoni JL, Scapulatempo Neto C, Alves MTS, Cohen M. Mecanorreceptores dos ligamentos cruzados do joelho. Rev Bras Ortop. 2005;40(9):534-42.

8. Colleoni JL, Rodrigues LM, Granata GSM Jr, Scapulatempo C, Abreu LC, Valenti VE, et al. Immunohistochemical analysis of mechanoreceptors in the human posterior cruciate ligament: association with aging male. Aging male. 2013;16(2):73-8.

9. Zhang K, Mihalko WM. Posterior cruciate mechanoreceptors in osteoarthritic and cruciate-retaining TKA retrievals: a pilot study. Clin Orthop Relat Res. 2012;470(7):1855-9.

10. Martins GC, Camanho G, Rodrigues MI. Immunohistochemical analysis of the neural structures of the posterior cruciate ligament in osteoarthritis patients submitted to total knee arthroplasty: an analysis of thirty-four cases. Clinics (São Paulo). 2015;70(2):81-6.

11. Franchi A, Zaccherotti G, Aglietti P. Neural system of the human posterior cruciate ligament in osteoarthritis. J Arthroplasty. 1995;10(5):679-82.

12. Del Valle ME, Harwin SF, Maestro A, Murcia A, Veja JA. Immunohistochemical analysis of mechanoreceptors in the human posterior cruciate ligament: a demonstration of its proprioceptive role and clinical relevance. J Arthroplasty. 1998;13(8):916-22

13. Vandekerckhove PJ, Parys R, Tampere T, Linden P, Van Den Daelen L, Verdonk PC. Does cruciate retention primary total knee arthroplasty affect proprioception, strength and clinical outcome? Knee Surg Sports Traumatol Arthrosc. 2015;23(6):1644-52.

14. Longo UG, Ciuffreda M, Mannering N, D'Andrea V, Locher J, Salvatore G, Denaro V. Outcomes of posterior-stabilized compared with cruciate-retaining total knee arthroplasty. J Knee Surg. 2018;31(4):321-40

15. Kahn HJ, Marks A, Thom H, Baumal R. Role of antibody to S100 protein in diagnostic pathology. Am J Clin Pathol. 1983;79(3):341-7.

16. Mihalko WM, Creek AT, Mary MN, Williams JL, Komatsu DE. Mechanoreceptors found in a posterior cruciate ligament from a well-functioning total knee arthroplasty retrieval. J Arthroplasty. 2011;26(3):504.e9-504.e12.

17. Cardullo RA. Fundamentals of image processing in light microscopy. Methods Cell Biol. 2003;72:217-42.

18. Schutte MJ, Dabezies EJ, Zimny ML, Happel LT. Neural anatomy of the human anterior cruciate ligament. J Bone Joint Surg Am. 1987;69(2):243-7.

19. Wikstrom EA, Tillman MD, Kline KJ, Borsa PA. Gender and limb differences in dynamic postural stability during landing. Clin J Sport Med. 2006;16(4):311-5.

20. Cug M, Wikstrom EA, Golshaei B, Kirazci S. The effects of sex, limb dominance, and soccer participation on knee proprioception and dynamic postural control. J Sport Rehabil. 2016;25(1):31-9 